\title{
MUDANÇAS POLÍTICAS E ECONÔMICAS QUE CONTRIBUÍRAM PARA O PANORAMA ATUAL BRASILEIRO DO MERCADO DE TRABALHO E EMPREGO
}

Rodrigo Gomes Alves

Mestrando do Programa de Pós-Graduação em Desenvolvimento Local do Centro Universitário Augusto Motta, Campus Bonsucesso, Rio de Janeiro, RJ galves.rodrigo@gmail.com

Gustavo Pedroso Malavota

Mestrando do Programa de Pós-Graduação em Desenvolvimento Local do Centro Universitário Augusto Motta, Campus Bonsucesso, Rio de Janeiro, RJ gustavo@malavota.com.br

Helen Gonçalves Romeiro Ferreira Mestranda do Programa de Pós-Graduação em Desenvolvimento Local do Centro Universitário Augusto Motta, Campus Bonsucesso, Rio de Janeiro, RJ helen.bioromeiro@gmail.com

Kátia Eliane Santos Avelar Doutora em Ciências pela Universidade Federal do Rio de Janeiro, UFRJ. Docente e Pesquisadora do Programa de Pós-Graduação em Desenvolvimento Local no Centro Universitário Augusto Motta, UNISUAM katia.avelar@gmail.com

\section{RESUMO}

Partindo de revisões bibliográficas de uma literatura voltada aos processos de formação e conceituação do termo "trabalho" e de suas ressignificações a partir do espaço e do tempo, compreende-se seu entendimento atual. Tendo observado o progresso histórico do labor, é possível traçar um panorama associando o conceito às fases pela qual o mercado, o trabalho e o emprego passaram no cenário nacional. Dessa maneira, traça-se um paralelo entre a relação do homem com o trabalho e pode-se definir a partir dessa relação uma sessão histórica do desemprego e de sua importância como definidor da sociedade brasileira, desde a virada do século $X X$ até os dias de hoje e como o aumento do desemprego e a diminuição dos postos de trabalho propiciaram o surgimento de movimentos de prestação de serviços foras dos padrões de emprego formal.

Palavras-chave: Desemprego. Brasil. Trabalho. Emprego. Mercado.

\section{POLITICAL AND ECONOMIC CHANGES THAT CONTRIBUTED TO THE CURRENT BRAZILIAN OVERVIEW OF THE LABOR AND EMPLOYMENT MARKET}




\begin{abstract}
Starting from a bibliographic revision of a literature headed to formation processes and conceptualization of the term "labor" and his resignifications from a spatial and temporal view, it is understood its current understanding. By observing the historical progress of labor, it is possible to develop an outlook associating the concept to the phases in which the market, the labor and the job elapsed in national scene. Thus, a parallel is made between men's relationship with labor and then can define by this relation a historic session of unemployment and its relevance as a definer in Brazilian society since the arrival of XX century till today. As the increase in unemployment and the decrease in jobs led to the emergence of service provision movements outside the formal employment patterns.
\end{abstract}

Key-Words: Unemployment. Brazil. Work. Job. Market.

Recebido em: $12 / 04 / 2020$. Aceito em: 22/10/2020. 


\section{INTRODUÇÃO}

A abordagem do trabalho vem sendo ressignificada ao longo do tempo. O surgimento da palavra remete, inicialmente, à ideia de tortura e sofrimento, pois trabalhar era atividade para as pessoas que perdiam sua liberdade. Ao exercer um trabalho, nós humanos, podemos estremecer diante de um estorvo. Tal estorvo pode ser invisível, pois, na verdade, é o estorvo da sociedade na falta de liberdade e independência. Isto é, o trabalho como privação do ser humano da capacidade de ser livre (KURZ, 1997, p. 3).

A partir disso, pode-se associar ao conceito de trabalho dentro da Bíblia, no qual a apresentação de trabalho está relacionada a uma necessidade que pode levar ao cansaço ou ser comparado a uma maldição citado nos Gênesis 3:19 "Comerás ao pão com o suor de seu rosto" (BÍBLIA, 2008). Segundo a Bíblia, o trabalho pode ser compreendido como obrigação, dever e responsabilidade. A igualdade entre trabalhar e sofrer não somente cansar-se, pode se representar também, uma condição social. Isso reitera a relação de trabalho como algo penoso, negativo (WOLECK, 2002).

A palavra trabalho pode ser conceituada de diferentes formas. Por ser abstrato, podemos classificá-lo como esforço físico ou mecânico ou como a energia gerada por animais, máquinas ou seres humanos (CATTANI, 1997).

Durante a antiguidade o trabalho de produção era feito por escravos, já na idade média esse posto foi ocupado pelos servos e, na atualidade, em uma sociedade capitalista, esse serviço é distribuído entre trabalhadores rurais e urbanos (LAZZARESCHI, 2007).

O trabalho organizado sob a forma de instituições, fábricas, associações, cooperativas e empresas é adotada como uma característica forte da sociedade contemporânea desde o período da Revolução Industrial. Máquinas e o alto índice de produção concentrou muitos trabalhadores. Os empregados estabeleceram vínculos e se engajaram no sistema de trabalho coletivo. Estas ações representam direta e indiretamente o meio de vida, o espaço e o objetivo real determinado para a vida das pessoas (LUCENA, 1995). 


\section{OBJETIVO GERAL}

Desenvolver uma revisão de literatura acerca do panorama geral do mercado de trabalho e emprego, desde os primórdios bíblicos até os dias atuais. Descrevendo a evolução do mercado de trabalho e histórico do emprego no Brasil.

\section{METODOLOGIA}

O presente trabalho refere-se a uma revisão bibliográfica sobre o panorama mercadológico de emprego e trabalho no Brasil, na qual foram coletados dados de artigos científicos, livros e através da ferramenta de busca Google acadêmico, Scielo. Os descritores pesquisados e analisados foram Desemprego, Brasil, Trabalho, Emprego e Mercado. Para este trabalho foram utilizadas publicações em português, referentes ao período de 1982 a 2019 . A busca foi executada entre os meses de março e junho de 2019.

\section{EVOLUÇÃO DO MERCADO DE TRABALHO NO BRASIL}

Há sessenta anos o Brasil teve como registro dois períodos bastante diferenciados no mercado de trabalho. O primeiro ocorrido entre 1930-1980 que tem o movimento, no qual o mercado de trabalho começa a se estruturar, que ocorre concomitantemente com o processo de industrialização e a implementação das relações e condições de trabalho. Foi uma época marcada pela importância do emprego assalariado, registrado formalmente e das ocupações nos segmentos organizados da economia. A partir de 1980, ocorreram fatores reversos na trajetória geral relacionadas ao emprego, acontecendo uma desestruturação do mercado de trabalho. O desemprego de parte da população economicamente ativa expandiu ocupações nos segmentos não organizados e o desemprego ocorreu em paralelo ao abandono do projeto de industrialização brasileiro. A adoção de políticas macroeconômicas causou o enfraquecimento do estatuto do trabalho. Em virtude das diferentes dinâmicas do mercado trabalhista, que depende do desenvolvimento geral da economia não devem ser buscadas somente no interior do mercado de trabalho. Se faz necessário entender as mudanças no padrão de desenvolvimento, rendimentos, novas formas de contrato trabalhista e o uso da 
força humana diante do trabalho. Sem estas análises, temos dados insuficientes e inconsistentes, tornando o diagnóstico errado (MORETTO; POCHMANN, 2004).

Ainda no início dos anos 80 houve uma reestruturação no movimento operário, decorrente da mobilização dos trabalhadores. Um dos fatores questionados foi a redução de índices de rotatividade nos postos de trabalho, colocando limites nas demissões em massa. Na época, mesmo com a produção em alta as taxas mantinham-se entre $15 \%$ e $30 \%$ ao ano. Os sindicatos não se envolviam profundamente nas relações e condições de trabalho, devido a ditadura militar, no qual o Estado controlava tudo e mantinha os trabalhadores sob ameaça de intervenção. Utilizava-se a rotatividade para disciplinar a força de trabalho, relacionadas a aceitabilidade salarial e às condições as quais as pessoas eram submetidas, sendo que esta relação de trabalho acabou favorecendo uma postura autoritária da política brasileira naquela década, entretanto a Consolidação das Leis do Trabalho (CLT) garantia o salário mínimo, jornada de trabalho e o 13 o salário, além de férias entre outro direito protegendo o empregado e impedindo o empregador de demitir sem justa causa (HUMPHREY, 1982).

Nos últimos 20 anos, os estudiosos sobre a duração do desemprego se destacaram na literatura internacional. Eles estudaram o desemprego expressivo no Japão e nos países da Europa, destacando a Áustria, França, Suécia, Suíça, que obtiveram índices crescentes de desemprego. Estudiosos Brasileiros em mercado ainda exploram pouco este tema, embora haja um aumento alarmante de desemprego nos últimos anos. Desde a década de 80 , o principal objetivo das autoridades monetárias era a desinflação, que foi alcançado quando o plano Real foi implementado. O plano baseava-se na valorização do câmbio e nas altas taxas de juros, controlando a inflação e elevando o déficit na balança comercial. Quando nos anos 90 foi iniciado o processo de liberação comercial, as empresas racionalizaram as atividades produtivas, aumentando a produtividade e a competitividade de seus produtos no mercado internacional. Nesse novo cenário, a economia do Brasil se depara com uma problemática incomum, o aumento das taxas e a duração do desemprego (PENIDO; MACHADO, 2002).

Segundo Bivar (1993), pioneiro sobre a duração do desemprego no Brasil é de seis meses. A autora encontra diferenças, em que o sexo interfere diretamente na taxa de saída do emprego.

A análise dos resultados expõe que a maioridade dos desempregados são mulheres, não chefes de família, além de constatar que os estudantes demoram um tempo maior a se incluírem no mercado de trabalho. Apontando também que quanto maior sua permanência 
no emprego anterior menor a probabilidade de recolocação profissional. Curiosamente profissionais da construção civil ou do setor de serviços, que não recebem FGTS conseguem um novo emprego com mais facilidade (PENIDO; MACHADO, 2002).

O povo brasileiro tem vivido grandes acontecimentos políticas e sociais envolvendo diversas instituições democráticas que ficou popularmente conhecido como Mensalão. Manifestos populares, o impeachment de Dilma Rousseff e a prisão do ex-presidente Lula repercutiram em diversas classes da sociedade brasileira e despertou interesse em pesquisadores, cientistas políticos e historiadores (PEIXOTO; CRESPO, 2018). Embora muito difundida nos meios de comunicação a palavra crise ainda é pouco compreendida.

Com o impeachment sofrido por Dilma, o vice Michel Temer, assume a Presidência da República com uma dívida bruta que supera $70 \%$ do PIB, que foi a maior entre os países da América Latina. A taxa de desemprego só aumentava, alcançando índices preocupantes e elevados. Em razão da crise na Petrobrás e a falta de investimentos acarretou na redução da atividade na indústria naval, fazendo com que o índice de desemprego subisse. Reformas da previdência, trabalhista, política e tributária pelo novo governo como necessárias para a resolução de problemas econômicos e políticos. O novo governo discursava, ter a solução para a crise, após anos de confiança do povo nos governos Dilma e Lula. O presidente Michel Temer assume e se denomina "ponte para o futuro. Sua imagem não era associada ao PT, mas como a solução para a retirada de Dilma Rousseff do poder. Esta apontada como uma das causadoras da crise brasileira e do desemprego no país (PEIXOTO; CRESPO, 2018).

A palavra crise, oriunda do grego, tem o significado de discriminação e decisão. O termo trazia a ideia de processos de decisão e julgamento, no sentido de uma tomada de decisão na solução (MENDES, 2001).

Mudanças e a reestruturação da produção que se ampliou pelo mundo, consequentemente, ocasionou intensas alterações e transformações sobre a esfera trabalhista e a classe trabalhadora. Vários países do mundo perceberam a expansiva redução do emprego. O desemprego aconteceu pela persistência contínua, elevados índices de demissões e na ampliação do tempo da procura de trabalho pelos indivíduos. As classes sociais com menor e maior grau de instrução sentiram a perda de seus postos de trabalho e renda. A ineficiência e a falta de qualidade do trabalho são verificadas através do crescimento das modalidades de ocupações flexíveis, como contrato de trabalho por tempo determinado, em tempo parcial, subcontratado, terceirizado, o trabalho autônomo e informal. Surgindo novas 
formas trabalhistas que fogem do padrão de trabalho legalmente constituído, na qual a maioria delas não estão assistidas pela legislação. Sendo assim, todos os direitos trabalhistas conquistados no início da Revolução Industrial, ocorrido na Inglaterra, passaram a ser adaptados, dispondo de uma mão de obra em função das necessidades imediatas do mercado trabalhista. Este processo atinge drasticamente a base social que historicamente compôs os movimentos trabalhistas, o que, por sua vez, levou a um enfraquecimento do poder sindical (PEDROSO, 2019).

\section{O HISTÓRICO DO EMPREGO NO BRASIL}

A partir disso, é preciso compreender a evolução histórica do desemprego no Brasil, a partir da ideia de trabalho apresentada anteriormente. Nessa ideia, é possível destacar alguns pontos que definem marcos no século $X X$. Quanto ao desemprego, isto é, um fenômeno econômico e social que se finda principalmente no pós-Revolução Industrial e define aquele.

Em uma visão macro, pode-se destacar alguns dados: de 1901 e 2000, a demografia do país partiu de 17,4 e chegou em 169,6 milhões de pessoas, sendo um contingente de $10 \%$ desse crescimento fazendo jus aos imigrantes. O PIB per capita, nesse período, multiplicou-se por 12 enquanto o PIB por 100. Ainda na economia, a média de inflação anual passou de $6 \%$ em 1930, antes da Era Vargas, chegando a 764\% de 1990 a 1995 até a queda de 8,6\% de 1995 a 2000 (IBGE, 2007).

Após observar em uma escala maior, pode-se observar de forma mais aprofundada cada uma das fases do trabalho no Brasil. Começando, em primeiro plano, pela década de 1920, anteriormente a Vargas, pode-se destacar a porcentagem de 4,4\% de Pessoas Sem Trabalho (PST), como exposto na Figura 1 (BARBOSA, 2008). 
Figura 1: Taxa de Desemprego em 1920

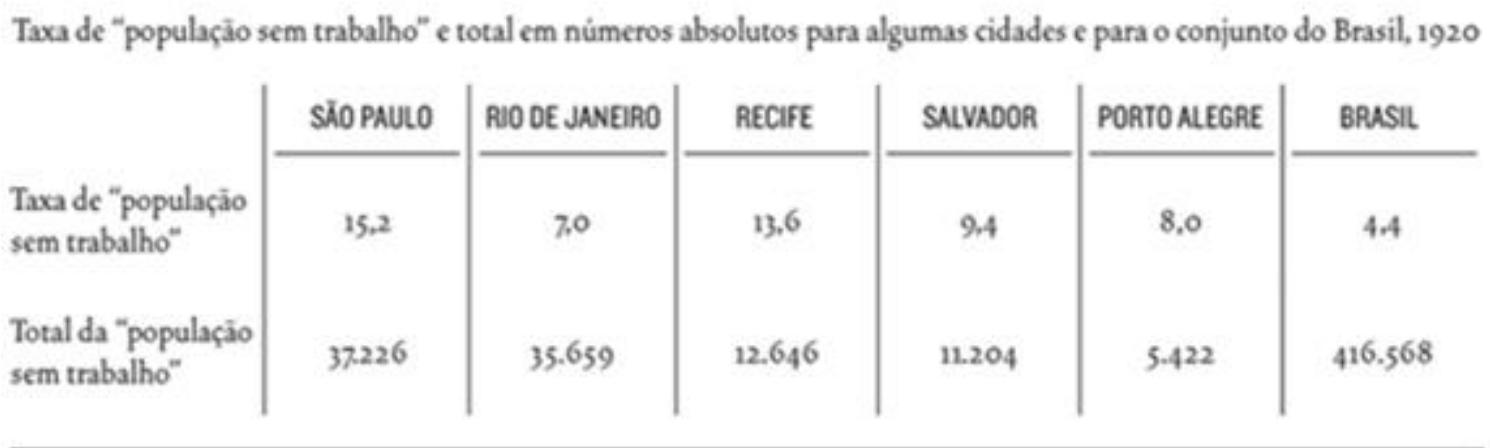

Fonte: BARBOSA (2008).

Observando uma lógica pós-abolição ainda recente, o trabalho livre era uma condição ainda muito jovem no Brasil. A industrialização e a lógica capitalista surgiam no país por meio da capital paulista, concentrando $20 \%$ do operariado do país na cidade. Nesse período, é possível destacar a precariedade do trabalho devido à ausência de direitos trabalhistas, associando-se à condições exaustivas da jornada, remuneração baixíssima, assim como a ocupação dos postos de trabalho qualificados por estrangeiros.

As afirmações destacadas acima podem ser reiteradas a partir das transformações promovidas na Era Vargas a partir do golpe de 1930 (SOUZA, 2005). Entre elas, a fixação da jornada de trabalho de 8 horas, o salário mínimo e até mesmo a chamada Lei de Cotas ou Lei dos $2 / 3$, que acentua o controle da entrada de imigrantes no mercado de trabalho brasileiro, ao obrigar as empresas a terem seu quadro de funcionários composto por brasileiros em $2 / 3$ do contingente (GERALDO, 2009).

Essa regulamentação estatal trabalhista de Vargas seguia a tendência ao keynesianismo e ao Estado de Bem-Estar Social originado no pós-Grande Depressão. Nesse momento, o trabalho assalariado se assenta no país. Seguindo uma lógica de desenvolvimento trabalhista, atravessando a era JK com os "50 anos em 5" e o plano de metas colocando a industrialização do país em esteira até aproximadamente o golpe de 64 . Pouco antes, surgia o Instituto de Estudos Políticos e Sociais (IPES), a elite intelectual que fundamentaria a gestão ideológica e política dos governos militares, formado por um grupo de empresários brasileiros e multinacionais, articulados com generais das forças armadas. A partir disso, em 1964 com o sucesso do golpe, a política desenvolvimentista foi substituída pela doutrina de interdependência - o modelo neoliberal no Estado (SAVIANI, 2008). 
Nesse período, destaca-se a injeção de capital estrangeiro no país gerando o "milagre econômico" proporcionando uma maior oferta de contratação de trabalhadores assalariados, principalmente para a manutenção da expansão da infraestrutura do país, causando, no entanto uma queda considerável do salário mínimo para propiciar um controle inflacionário maior, como pode ser visto na Figura 2.

Figura 2: Série Histórica do Salário Mínimo Real, 1958-2018: Crescimento constante ao longo dos últimos 20 anos.

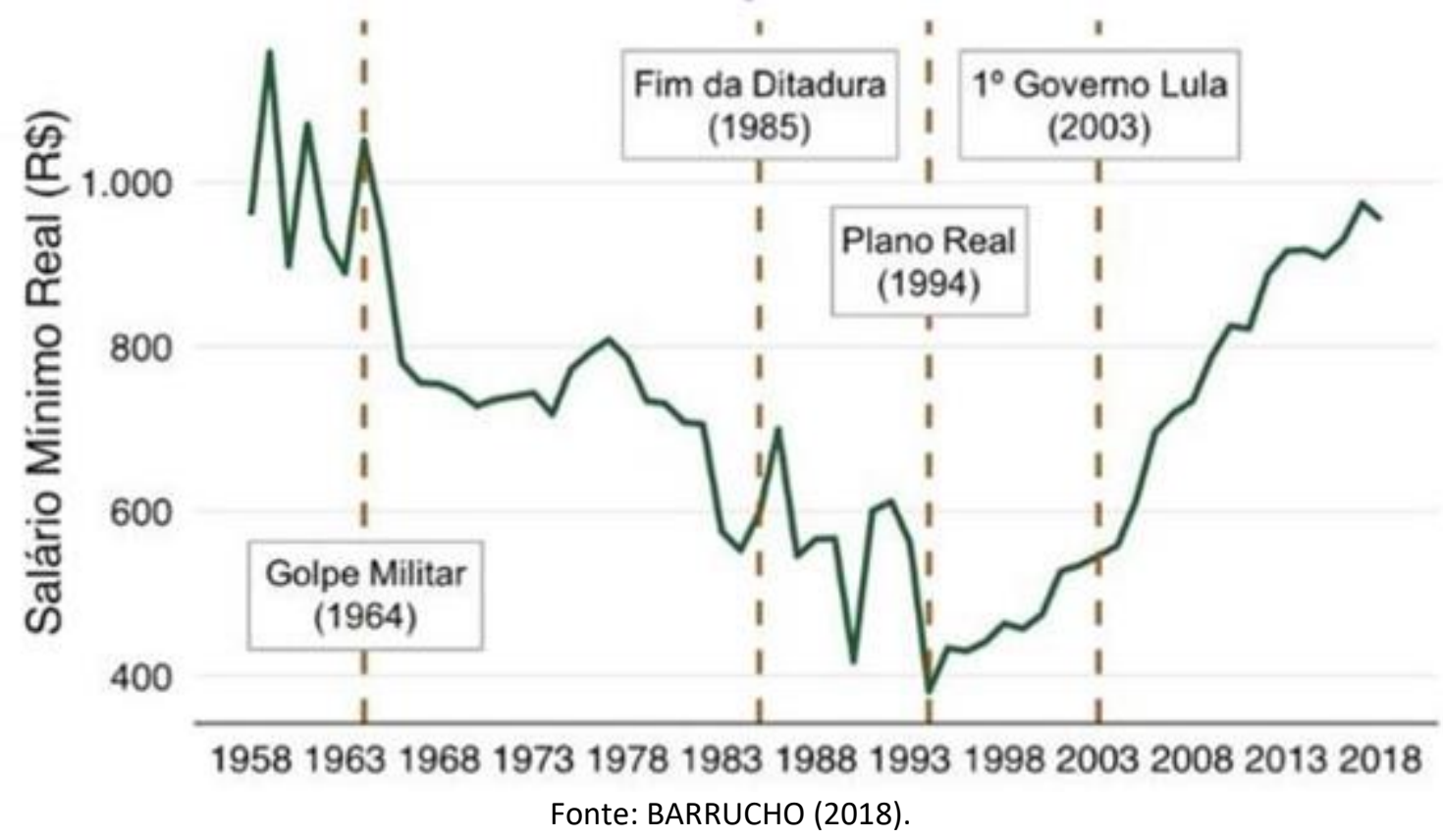

Com as subsequentes crises do petróleo, o fim do milagre econômico, o descontrole da inflação e a crise política a partir dos anos 80 , somando-se a precarização do trabalho por uma medida de ideologia individualista, prezando pela inserção da lógica de prestação de serviços no lugar de trabalho e a subutilização da força de trabalho, o desemprego se tornou um problema: a situação de subemprego, se estendendo do governo Sarney ao Collor (ARANDIA, 1991).

No século XXI, o Brasil se insere no contexto da globalização a partir da Revolução Técnico-Informacional, que traz transformações latentes no emprego. De 2003 a 2010, a Taxa de Desemprego Aberto percentual variou de $12,3 \%$ ao ano para $6,7 \%$ ao ano. Ao fim do segundo mandato de Fernando Henrique Cardoso, o Brasil ocupava a segunda posição no ranking de desemprego mundial (Figura 3). 
Figura 3: Taxa de Desemprego em \% no Brasil de 2003 a 2010

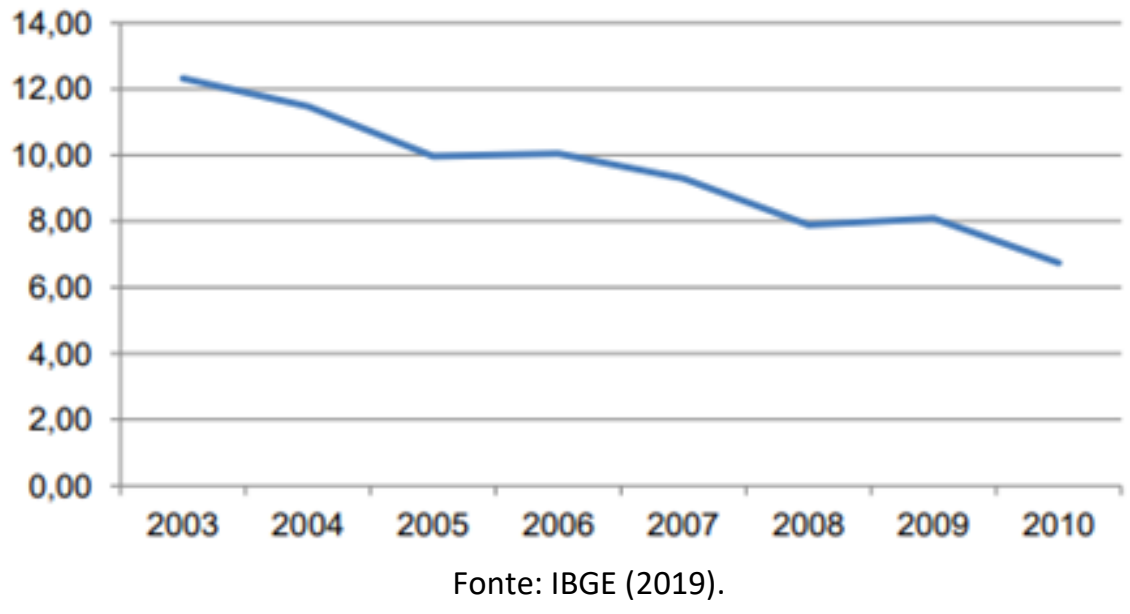

Ao analisar o governo de FHC, destaca-se um momento posterior à implementação do Plano Real, contribuindo para contingência e estabilização da moeda que influenciou diretamente no saneamento de bancos federais, na política de austeridade e privatizações para angariar capital, assim como o redirecionamento da economia do país com a adoção do tripé macroeconômico, pautado em metas de inflação, câmbio flutuante e superávit primário. Com a nova política econômica adaptada, os juros e a inflação foram controlados, mas ao custo de uma elevação do desemprego a taxas nunca antes vistas, ligadas principalmente à política de privatizações (39 empresas, no total), que geraram cortes expressivos no número de funcionários da empresa (CHRISTO, 2013). Ao visar a atração de capital externo, houve uma abertura comercial que enfraqueceu o desenvolvimento brasileiro e propiciou o aumento do desemprego e do trabalho informal no país (FARIA, 2004).

Em 2002, com a Carta ao Povo Brasileiro, Lula consegue dar o recado aos investidores brasileiros, afirmando o compromisso com a política econômica que havia sendo proposta, quebrando a desconfiança que havia sobre a ruptura política e, portanto, elegendo Lula ao seu primeiro mandato. Ao longo de seu mandato foi se cumprindo as promessas feitas assim recuperando os investidores e continuando no futuro segundo mandato a mesma política fiscal que foi adotada no seu governo anterior, trazendo consigo um maior controle inflacionário. Com um aumento de políticas socioeconômicas, como o Bolsa Família, o governo ampliou o acesso da população em miséria à direitos básicos e ampliou a demanda interna e movimentação de moeda, fortalecendo o crescimento e reduzindo o desemprego por sua vez. 
Pela primeira vez, observa-se o aumento do emprego formal correlacionado ao aumento do salário mínimo. De 2003 a 2010 foram criados mais de 15 milhões de postos de trabalho no país, tendo saldo positivo em todos os anos, como pode-se observar na Figura 4.

Figura 4: Geração Líquida de Emprego 2003 - 2010

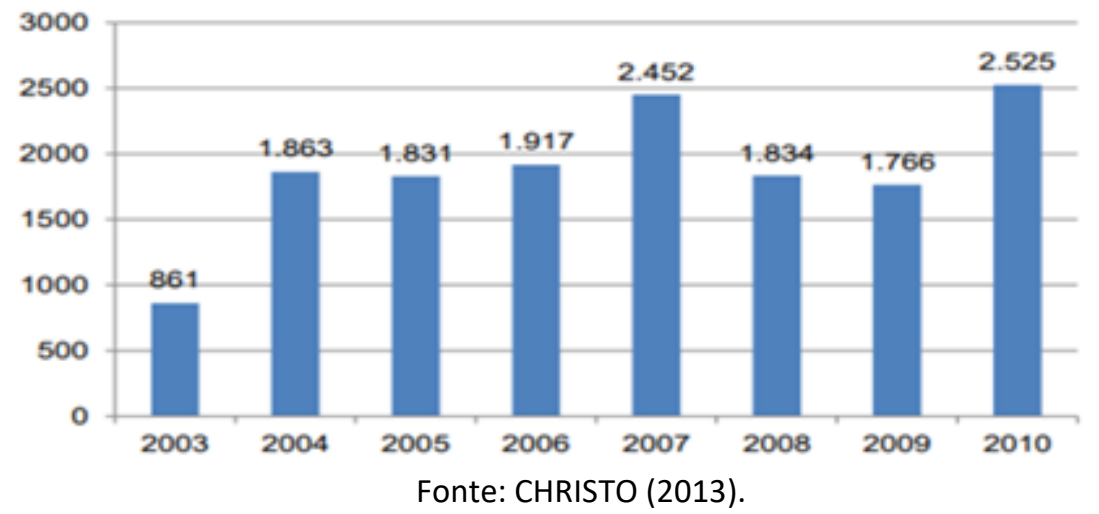

Com a redução da influência externa no país e a ampliação da demanda interna através de políticas de redução de juros, aumento do investimento público (obras como o Programa de Aceleração do Crescimento - PAC) , ampliação do crédito e distribuição de renda por meio de políticas como o próprio Bolsa Família que propiciou um aquecimento da economia sem a queima de postos de trabalho, expandindo a produção em um ciclo virtuoso, gerando a demanda de empregos cada vez maior e deixando seu segundo mandato com a taxa de desemprego em 6,7\%.

Posteriormente a esse período, na fase Dilma, seu primeiro mandato reproduz a política econômica de Lula, mas destaca-se pelo controle inflacionário do preço da gasolina e da energia elétrica. A crise econômica rompeu e com ela a crise política, levando à articulação do impeachment. Dilma assume com o desemprego em 6,8\%, atinge o valor de $4,3 \%$ duas vezes (em dezembro de 2013 e 2014) para deixá-lo em 11,8\% com a saída por impedimento, como pode ser visto na série histórica exposta na Figura 5 (IBGE, 2019). 
Figura 5: Gráfico da Série Histórica da Taxa de Desemprego de 2012 a 2019.

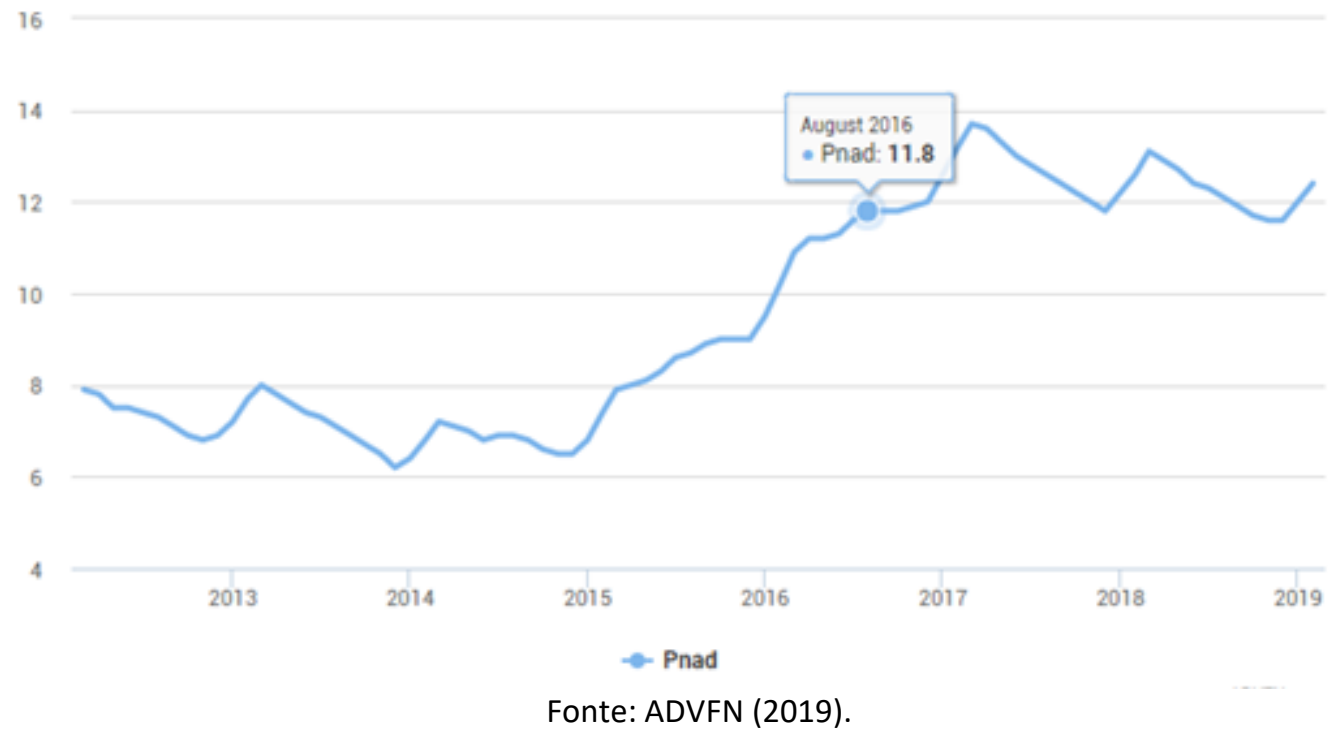

A partir do impeachment, com a entrada do presidente Michel Temer há um rompimento com o modelo econômico anterior. Em uma lógica de flexibilização das leis trabalhistas (BRASIL, 2017a) e de terceirização (BRASIL, 2017b) retornam o Brasil à uma política de precarização do trabalho e prestação de serviços, continuando até a contemporaneidade. Em março de 2019, a porcentagem era de 12,7\% de desempregados. Em números totais, somam 13,4 milhões. No contexto de subutilizados, o número foi de 28,3 milhões de pessoas, sendo recorde (IBGE, 2019).

\section{CONSIDERAÇÕES FINAIS}

A mudança na relação do homem com trabalho ao longo dos séculos é evidente, que antes era visto como um castigo hoje é essencial a sua existência, sendo que os frutos do seu trabalho geram satisfação profissional e pessoal trazendo status social do qual pode se orgulhar; já o indivíduo que não possui nenhum tipo de emprego é visto como à margem da sociedade.

No Brasil, podemos observar diferentes cenários no mercado de trabalho que tem forte correlação com o momento político do País desde a década de 20 até os dias atuais.

Atualmente tais variações podem ser associadas à ideia de empregabilidade neoliberal inserida por meio de isenções fiscais e perdão de dívidas assumindo que este capital seria reinserido na economia por meio de novos postos de trabalho. Entretanto, ao observar 
o crescimento do desemprego e a queda dos postos de trabalho pós-aprovação das leis de flexibilização, presume-se que a política ainda não tenha surtido efeito.

De maneira análoga, surgem certos movimentos também inseridos na lógica de prestação de serviços. Exemplos disso são os entregadores de comida sem nenhum tipo de contrato trabalhista, como iFood, Glovo, Rappi. Em outro setor, os motoristas da Uber também entram nessa lógica. Ao unir o desemprego, a precariedade e a necessidade de sobreviver, o exército de reserva de mão de obra opera aceitando todo o tipo de trabalho, por mais precário e mal remunerado que este seja.

Os empregos temporários não parecem como alternativa temporária a crises econômicas. Percebemos que a instabilidade e flexibilidade nas vagas oferecidas formam um novo contexto naquilo que hoje chamamos de mercado de trabalho, levando a crer que no futuro surgirão outras formas trabalho, que podem não estar ligadas aos modelos de emprego formal e nem abarcando todos os direitos previstos na legislação vigente do Brasil.

\section{REFERÊNCIAS}

ADVFN. Pnad. 2019. Disponível em: https://br.advfn.com/indicadores/pnad. Acesso em: 21 maio de 2019.

ARANDIA, A. K. O mercado de trabalho frente a crise dos anos 80 e aos planos de estabilização. Indicadores Econômicos, v. 18, n. p. 148-164, 1991.

BARRUCHO, L. 50 anos do Al-5: Os números por trás do 'milagre econômico' da ditadura no Brasil, BBC NEWS, dez. 2018. Disponível em: https://www.bbc.com/portuguese/brasil45960213/. Acesso em: 13/10/2019.

BARBOSA, A. F. O Mercado de Trabalho Antes de 1930. Novos Estudos CEBRAP, São Paulo, ed. 80, p. 91-106, mar. 2008.

BÍBLIA, A. T. Genesis. In: BÍBLIA. Português. Sagrada Bíblia Católica: Antigo e Novo Testamentos. São Paulo: Sociedade Bíblica de Aparecida, 2008. Gn. 3:19.

BIVAR, W. S. B. Aspectos da estrutura do desemprego no Brasil: composição por sexo e duração. Rio de Janeiro: BNDES, 1993. 101p. 17ㅇ Prêmio BNDES de Economia, 1993; originalmente apresentada como Dissertação (Mestrado) - Pontifícia Universidade Católica do Rio de Janeiro, 1991.

BRASIL. Decreto-lei no 13.467, de 13 de julho de 2017. Brasília, DF: Presidência da República: 2017. Disponível em: http://www.planalto.gov.br/ccivil_03/_ato20152018/2017/lei/l13467.htm. Acesso em 20 maio de 2019. 
BRASIL. Decreto-lei no 13.429, de 31 de março de 2017. Brasília, DF: Presidência da República: 2017. Disponível em: http://www.planalto.gov.br/ccivil_03/_Ato20152018/2017/Lei/L13429.htm. Acesso em 20 maio de 2019.

CATTANI, A. (Org.). Trabalho e tecnologia: dicionário crítico. Petrópolis: Vozes, 1997. p. 292.

CHRISTO, D. C. Evolução do desemprego no Brasil de 1995 a 2010: análise dos governos FHC e Lula. 2013. Trabalho de Conclusão de Curso (Graduação em Ciências Econômicas) Faculdade de Ciências Econômicas, Universidade Federal do Rio Grande do Sul, Porto Alegre, 2013. Disponível em: https://www.lume.ufrgs.br/handle/10183/97647. Acesso em 19 maio 2018.

FARIA, L. A. E. Aquém da estagnação: 10 anos do Plano Real. Indicadores Econômicos FEE, Porto Alegre, v. 32, n. 2, 2004, p. 175-196.

GERALDO, E. A “lei de cotas" de 1934: controle de estrangeiros no Brasil. Cadernos AEL, Campinas, v. 15, n. 27, 2009.

HUMPHREY, J. Fazendo o "milagre". Controle capitalista e luta operária na indústria automobilística brasileira. São Paulo: Vozes, 1982.

IBGE. Estatísticas do século XX. Rio de Janeiro, 2007.

IBGE. Pesquisa Nacional por Amostra de Domicílios: 2019. Rio de Janeiro, 2019. Disponível em: https://www.ibge.gov.br/estatisticas/sociais/educacao/9171-pesquisa-nacional-poramostra-de-domicilios-continua-mensal.html?=\&t=destaques. Acesso em 11 out 2020.

KURZ, R. A origem destrutiva do capitalismo: modernidade econômica encontra suas origens no armamentismo militar. Folha de São Paulo, São Paulo, 30 mar. 1997, c.5, p.3.

LAZZARESCHI, N. Trabalho ou emprego? São Paulo: Paulus, 2007.

LUCENA, Maria Diva da Salete. Avaliação de desempenho. São Paulo: Atlas, 1995.

MENDES, A. M. M. Subsídios para uma Teoria das crises políticas. In: Livro de Actas do 40 Congresso da Associação Portuguesa de Ciências da Comunicação, Aveiro, SOPCOM , p. 765774. Comunicação apresentada ao I Congresso Ibercom, Málaga, 2001. Disponível em: http://www.bocc.ubi.pt/pag/mendes-antonio-subsidios-teoria-crises-politicas.pdf. Acesso em: 20 maio de 2019.

MORETTO, A.; POCHMANN, M. A retomada do emprego numa economia em marcha lenta: implicações para as políticas públicas de mercado de trabalho. In: ENCONTRO NACIONAL DE ESTUDOS POPULACIONAIS, 14, 2004, Caxambu. Anais [...]. Caxambu: ABEP, 2004. 
PEIXOTO, V.; CRESPO, R. A. A crise política brasileira dos anos 2000 e o governo de Michel Temer. Em construção: arquivos de epistemologia histórica e estudo de ciência, v. 4, p 132145. 2018.

PEDROSO, M. O trabalho e suas transformações: uma análise sobre o brasil no final do século 20. UNIJUI, 2019.

PENIDO, M.; MACHADO, A. F. Desemprego: evidências na duração do Brasil metropolitano. In: ENCONTRO NACIONAL DE ESTUDOS POPULACIONAIS, 13., 2002, Ouro Preto. Anais [...]. Ouro Preto: abep, 2002.

SAVIANI, D. O legado educacional do regime militar. Cadernos Cedes, Campinas, v. 28, n. 76, p. 291-312, set./dez. 2008. Disponível em: http://www.cedes.unicamp.br.

SOUZA, A. P. A. Os direitos sociais na Era Vargas: a Previdência Social no processo histórico de constituição dos Direitos Sociais no Brasil. São Luís, 2005.

WOLECK, A. O trabalho, a ocupação e o emprego: Uma perspectiva histórica. Revista de Divulgação Técnico-científica do Instituto Catarinense de Pós-Graduação, v. 1, p. 33-39, jan. 2002. 